\title{
Investigación académica y gobernanza ética: una perspectiva sobre la creación de información
}

\author{
A brief account of Research Ethics
}

\author{
Alan GILCHRIST \\ The Cura Consortium, Reino Unido, alangilchrist77@googlemail.com
}

\begin{abstract}
Resumen
Se revisa brevemente el problema de la ética de la investigación científica, tanto como un tema de interés potencial para las personas que llevan a cabo investigación en el campo de la ciencia de la información, como por sus relaciones con diversos aspectos de la ética de al información.
\end{abstract}

Palabras clave: Ética de la investigación. Biblioteconomía y Documentación.

\section{Introduction}

Research ethics should be of concern to anyone conducting research in the library or information science areas but furthermore, as research is one of the starting points in the information chain it might be interesting to compare research ethics to information ethics to see what similarities and overlaps there might be. Clearly they are both aspects of ethics but this is not very helpful, particularly when one considers this word, which is a branch of philosophy sometimes referred to as moral philosophy. It is possible to be a little clearer by recognizing that there is a branch of ethics called applied ethics which clearly includes both information ethics and research ethics, for both of which (particularly the latter) professional organizations have laid down guidelines of good practice. It must be stressed at the start that these guidelines, some of which will be discussed below are no more than guidelines, though they may be supported by relatively strict governance procedures. In general, most people are more comfortable with dichotomies, selecting between two choices, but ethical issues are usually multifaceted and possible actions will invoke many different results each of which must be evaluated. The guidelines, then, attempt to reduce this inherent uncertainty to more manageable proportions.

\section{Genesis}

Not surprisingly the vanguard in the research ethics area has been in the medical sciences

\begin{abstract}
Research ethics is briefly reviewed, both as being of potential interest to those conducting research in library or information science, and as a comparison with aspects of information ethics.
\end{abstract}

Keywords: Information ethics. Information science.

and practice. It could be argued that Hippocrates of Cos was the first to consider medical ethics, when he wrote the Hippocratic Oath defining good medical practice and morals (though it is now thought that it was actually written by one or more of his followers in the $4^{\text {th }}$ Century BCE). Much nearer our own age, the lead seems to have been taken by the World Medical Association which issued what is known as the Declaration of Helsinki in 1974, and which saw its sixth revision in 2008. The fundamental principle is respect for the individual, their right to self determination and the right to make informed decisions regarding participation in research, both initially and during the course of the research. It would appear that this principle has been followed in other areas of research, particularly and most relevantly in the social sciences.

\section{UK Universities}

I am starting with UK Universities because this is where I have gathered what little understanding I have of research ethics as the lay member of a University Faculty Research Ethics and Governance Committee. The Faculty in question includes Computing, Mathematics, Information Sciences and, till recently, Business Studies. It is the latter two that are most subject to the need for guidelines on ethics research. There is nothing in the University's guidelines that differs in any important respect from the fundamentals contained in previously constructed guidelines; the only difference being that the University has 
seized the opportunity to include guidelines to address the quality of research and the reputation of the University. Most of the work, therefore, has been applied to complex and costeffective governance issues that will not be discussed here.

What I have, though, been unable to find anywhere else is the guideline "Research should be carried out where possible to avoid any potential or psychological harm, pain, discomfort or stress to participants, including the researchers themselves" [My italics]. In passing, one wonders about the unfortunate Marie Curie who killed herself with radioactive poisoning, and the various medical researchers who have subjected themselves to, for example, mosquito bites in order to further research into treatment for malaria. An interesting extra dimension to this issue of harm to the researcher is provided by Jef Akst (2010), writing in the journal The Scientist, which reports:

With attacks against animal researchers on the rise, three biomedical research groups compiled a guide to scientists for properly responding to requests for data and records while protecting themselves from animal rights activists who may take the information out of context and use it for harassment.

\section{Research ethics in the social sciences}

Just as there are many websites concerned with research ethics in the medical sciences, so there are in the social sciences, two of which are now presented. The first is one established by the UK Economic and Social Research Council [2], which starts with some useful definitions. First of all

\begin{abstract}
"Research" is defined as any form of disciplined enquiry that aims to contribute to a body of knowledge or theory". Second, " 'Research ethics' refers to the moral principles guiding research, from its inception through to completion and publication of results and beyond - for example, the curation of data and physical samples after the research has been published". Lastly " 'Human participants' (or subjects) are defined as including living human beings, beings who have recently died [...] and human data records (such as, but not restricted to medical, genetic, financial, personnel, criminal, or administrative records and test results including scholastic achievements".)
\end{abstract}

One of the more interesting websites is one put up by the Institute for Employment Studies which presents detailed guidelines under the title RESPECT [3]. It starts with the statement:

The RESPECT code is based on a synthesis of the contents of a large number of existing professional and ethical codes of practice, together with current legal requirements in the EU. Whilst the RESPECT provisions are voluntary, some of the requirements are morally binding on the members of specific professional associations or legally binding on citizens of EU Member States.

The Guidelines are helpfully presented in three sections:

- Upholding scientific standards

- Compliance with the law

- Avoidance of social and personal harm.

Phrases of concern to the library and information science community relate to both the conduct of the research and its reporting, thus for example:

Factual accuracy...or misinterpretation of data...;

Acknowledge fully any debts to previous research $[\ldots]$;

Demonstrate an awareness of the limitations of the research $[\ldots]$;

Ensure the research findings are reported accurately, comprehensively and without distortion". And in the light of scandals relating to skewed research commissioned by some companies in the pharmaceutical and tobacco industries:

Declare conflict of interest that may arise in the research funding or design.

\section{$[\ldots]$ and $[\ldots]$}

Declare the source of funding in any communications about the research.

The legal section presents detailed accounts of Data Protection and Intellectual Property laws, and also draws attention to other laws concerning health and safety, and employment and anti-discrimination, all of which can be relevant to information ethics. The third section returns us to the interactions between researchers and participants with such injunctions as:

[...] voluntary participation on the basis of informed consentí [...];

[...] protected from undue intrusion, distress, indignity, physical discomfort, personal embarrassment or psychological or other harm;

[...] ensure that research results are disseminated in a manner that makes them accessible to the relevant social stakeholders;

[...] ensure that research is commissioned and conducted with respect for all groups in society regardless of race, ethnicity, religion or culture, and with respect for and awareness of gender or other significant social differences.

\section{Concluding remarks}

While it can be argued hat both research ethics and information ethics have their roots in moral philosophy, it seems self-evident that the sup- 
porting guidelines, as products of applied ethics are pragmatic common-sense check-lists and supporting procedures based on the simple virtues of value, trust and respect. They combine elements of good professional practice with the underlying principle of "do no harm", and are cognizant of relevant existing laws such as those that govern data protection and intellectual property. Nevertheless, they are valuable reminders of moral values that should be understood and followed by all to whom they are addressed.

The most obvious overlap between the two areas of research ethics and information ethics is probably that which relates to the preparation and dissemination of research results. That this process is important to the library and information science community is obvious, and though less obvious to the average web surfer is still important. One of the most common observations by the more informed teachers concerning their student's use of the Web is that very few are capable of evaluating their search results; and this problem is not confined to the young but to most people, even trained intermediaries. Now, it is not the job of the professional intermediary to evaluate the content of research reports - they are not polymaths, nor is it their job - but they should be able to assess the status of the resource. The days are fading when it was possible to say with authority that "Publisher $X$ is reliable", or that "University Department $Y$ has an excellent reputation"; the Web is now too vast and a more intelligent appreciation and consideration of the signs is necessary. The commonly found and unsubstantiated statements to be found on websites (and in the newspapers) that "Research shows that..." or "It has been proved that..." are inadequate. It helps if the website publisher follows the guidelines concerning dissemination by being transparent about the research methodology, shortcomings and so on. This is what is meant in the definition of 'Research' quoted earlier as 'disciplined enquiry', followed by responsible reporting.

Tilburg University (a reliable source?) calculates that the size of the indexed Web is now at least 27.53 billion pages, and is still growing fast [4]. The Miniwatts Marketing Group (a reliable source??) calculates that the number of users of the Internet is just under 2 billion. With such huge numbers, commonly found in various sources, their accuracy hardly matters; the world is changing rapidly and in ways difficult to understand as the electronic wave accelerates. Now that everyone with a PC is a potential author, publisher, librarian, information scientist and researcher, it becomes very difficult indeed to promote universal guidelines of applied ethics. The re- cent example of the WikiLeaks story is instructive and thought-provoking. Julian Assange, an Australian Internet activist and journalist, variously described as "The monk of the Internet" and "A war criminal", hacked into Pentagon files (research?) and made available (publication) some 92,000 field reports concerning the war in Afghanistan. In doing so, he tried hard to cut out any material that might cause physical harm, even asking the Pentagon for guidance. He then provided the information to three national newspapers: The British The Guardian, the American New York Times and the German Der Spiegel. It is not relevant here to go into further details of the information released nor the possible consequences, merely to highlight the capability and the rationale of its instigator. Two quotes have been attributed to Assange: "You can't publish a paper on physics without the full experimental data and results; that should be the standard in journalism." and "You have to start with the truth. The truth is the only way that we can get anywhere. Because any decision-making that is based upon lies or ignorance can't lead to a good conclusion". It is worth noting that Assange was the winner of the 2009 Amnesty International Media Award for exposing extra-judicial assassinations in Kenya, which led to riots and deaths but the resumption of democracy.

All of which underlines the multifaceted nature of issues relating to moral decision-making. One is thrown back on the words of the great philanthropist Jeremy Bentham who said: "It is the greatest good to the greatest number of people which is the measure of right and wrong".

\section{References}

Askt, Jeff (2010). Tips to safely provide records. // The Scientists.com. 2010-01-15. http://www.the-scientist.com /blog/display/56276/ (2010-08-04)

ESRC society today. http://www.esrcsocietytoday.ac.uk lesrcinfocentre/opportunities/research_ethics_framework (2010-08-04)

The respect code of practice. http://www.respectproject.org /code/ (2010-08-04)

WorldWideWebSize.com. http://www.worldwidewebsize.com/ (2010-08-05)

Internet World stats. http://www.internetworldstats.com/stats. htm (2010-08-05)

Recibido: 23-08-2010. Aceptado: 23-08-2010. 
